\title{
Early Assessment of Integrated Knowledge Translation Efforts to Mobilize Sex Workers in Their Communities
}

\author{
Cecilia Benoit ${ }^{1}\left[\right.$ (] Róisín Unsworth $^{1}$
}

Received: 3 February 2020 / Revised: 9 June 2020 / Accepted: 16 June 2020 / Published online: 31 July 2020

(c) Springer Science+Business Media, LLC, part of Springer Nature 2020

\begin{abstract}
Researchers have recently increased their efforts to find more effective strategies to reduce the gap between the production of academic knowledge and its uptake in policy and practice. We focus attention on sex workers in Canada who have limited access to societal resources and are hampered by punitive laws prohibiting their work. The initial aim of our study was to work with sex worker organizations and allied agencies to develop a training program for sex workers to help them understand Canada's most recent criminal justice approach to adult sex commerce. What has emerged from our integrated knowledge translation process during the first year of the study's operation has been a change to a broader focus on mobilizing sex workers around their occupational and social rights. In this paper, we first give an overview of recent changes in Canada's prostitution laws and then report qualitative findings from interviews with members of our partner organizations. Interviewees appreciated the change in research direction and the emergent collaborative process among themselves and the authors, but also noted challenges regarding shifting research timelines, balancing power between themselves and the academic researchers, and reaching consensus on research plans among community partners themselves. We discuss the findings in relation to successful knowledge translation strategies that aim to ensure the research questions we ask, and the empirical processes we engage in, are advantageous to those we aim to benefit.
\end{abstract}

Keywords Participatory research $\cdot$ Integrated knowledge translation $\cdot$ Collaborative governance $\cdot$ Sex workers · Mobilization

\section{Introduction}

Across countries today, academic or scientific knowledge holds a powerful place in civic discourse and the holders of that knowledge, specifically university-trained researchers, are awarded special status. Other kinds of knowledgelay/experiential/everyday/Indigenous - is not granted such public acknowledgment and those holding it are given less recognition. One outcome is the knowledge translation challenge or 'know-do gap' between the so-called researcher and research user (Hunter, 2019). This disconnect between academic research findings and their real-world application is especially regrettable for people who face social injustices due to their disadvantaged structural location, nonnormative sexual identities, or illicit behaviors. They, and

Cecilia Benoit

cbenoit@uvic.ca

1 Department of Sociology, Canadian Institute for Substance Use Research, University of Victoria, 2300 McKenzie Ave., Victoria, BC V8N 5M8, Canada the community organizations providing them outreach, are regularly excluded from the research focused on them (BelleIsle, Benoit, \& Pauly, 2014; Cargo \& Mercer, 2008; Flicker et al., 2009; Jürgens, 2005; Norman \& Pauly, 2013).

Sex workers and the "underground organizations" supporting them are a case in point (Anasti, 2017, p. 418). Much of current academic scholarship links commercial sex to slavery, tags it as human sex trafficking, and places the spotlight on the victimhood of "prostituted women" (for a critique, see Bernstein, 2010; Mac \& Smith, 2018; Platt et al., 2018). These studies rely on survey or interview data with survivors recruited on the street, border crossings, shelters, or prisons. Results are then generalized to all people who provide sexual services for money (Benoit, Jansson, Smith, \& Flagg, 2019). Policy responses emerging from this body of research includes the use of criminal laws to prohibit commercial sex, media, and other campaigns to condemn it, and exiting programs for workers and rehabilitation programs for men who purchase sex (Thomas, 2009). Active sex workers and the organizations providing peer support and advocacy on their behalf are routinely 
not invited to the research table (Anasti, 2017; Hoefinger et al., 2019).

Authentic community-academic partnerships, where nonacademic partners are able to have a voice in research design and decision-making power regarding the research process, can improve the relevance of academic research for socially excluded groups (Minkler, 2010). Participatory research (PR), where the community contributes to all phases of the research, attempts to balance power between community partners and academics by bringing them together as co-researchers. PR, though difficult to accomplish in practice, has the potential to democratize information gathering, bridge the knowledgepractice gap, and foster conditions that accelerate agency for people at the bottom of vulnerability hierarchies (Cargo \& Mercer, 2008). These include:

the "victims" of social and environmental injustice themselves as well as community organizers, public health workers, and policy makers, for example, who struggle to bring scientific evidence to bear on the problems confronting their communities because of insufficient power and resources (Cargo \& Mercer, 2008, p. 330).

In this way, PR shares similarities with the knowledge-to-action (KTA) framework that includes two separate but overlapping components-knowledge creation and action cycle, each of which contain various interacting stages (Graham et al., 2006). Both structures share a central aim to bridge the divide between research findings and uptake in communities and champion the idea that diverse communities have specific cultures of understanding and exchange between them is neither guaranteed, nor usual. Both frameworks also embrace integrated knowledge translation (IKT), a two-way iterative process, ideally between equal partners actively engaged in creating knowledge and translating results for real-world relevance (Bowen \& Graham, 2013; CIHR, 2015; Field, Booth, Ilott, \& Gerrish, 2014). Gagliardi, Berta, Kothari, Boyko, and Urquhart (2015) state in regard to health research that "collaborative knowledge generation, as promoted through IKT approaches, involves ongoing, dynamic interactions among researchers and decision-makers, and represents an ideal means by which to address complex health care problems" (p. 2). Such collaborative projects involve initial investment in team-building strategies aimed at learning about the various needs and challenges of community organizations, working to develop a shared conceptual framework and research culture, while identifying and refining research questions and other common priorities (Benoit, Jansson, Millar, $\&$ Phillips, 2005). Through shared power and inclusion in decisions that affect their lives, tokenism is avoided and community representatives can use their voice and gain opportunities to make decisions in their best interest and that of their allies (Bess, Prilleltensky, Perkins, \& Collins, 2009).

More specific to marginalized groups criminalized by punitive laws, which includes sexual minorities in many countries and sex workers globally, Wagenaar, Amesberger, and Altink (2017) call for a focus on "collaborative governance" where interested parties come together in collective interchanges to participate in consensus-oriented decision making about policies that regulate social life (p. 231). This involves a "move away from expert-driven policy-making models towards processes that facilitate two-way information flow, and in doing so, transfer some decision-making power to citizens" (Masuda, McGee, \& Garvin, 2008, p. 360). Academic researchers need to capture "the lived experiences of sex workers' rights, organizing, and activism" (Lowthers, Sabat, Durisin, \& Kempadoo, 2017, p. 1). By doing so, we ask more meaningful questions, get more accurate answers, and likely become more successful in swaying public policies.

Below, we document and evaluate the IKT research process (Bowen \& Graham, 2013; CIHR, 2015; Gagliardi et al., 2015) we have been engaged in during the first year of operation of one PR project-Beyond 'Missing Women': Empowering Sex Workers as Social Justice Advocates. The initial aim of the project was to work in collaboration with sex workers and sex worker organizations to better understand the strengths and weaknesses of Canada's criminal justice approach to adult sex commerce. What has transpired has been an alteration in the research program to focus on mobilization of sex workers in their communities around their occupational and social rights. Interviews with members of participating sex worker and allied organizations reveal their support for the change in research direction and the emergent collaborative process among themselves and the authors, but also challenges regarding shifting research timelines, balancing power between themselves and the academic researchers, and reaching consensus on research plans among community partners themselves.

Before presenting the research project and the results of the interviews, we give a brief historical overview of sex work governance in Canada. This background information shows that $\mathrm{PR}, \mathrm{IKT}$, and collaborative approaches are rarely implemented in the legal history of sex work in Canada.

\section{Literature Review}

\section{Canada's Prostitution Laws}

The last half century of policy-making in Canada relating to adult sex work regulation has failed to take the views of sex workers into account, with a few exceptions. Prior to 2010, Canada's prostitution laws mirrored those of its former colonizing power, Britain, where sex commerce among consenting adults is not technically illegal, but the regulations are such that it is virtually impossible for sex workers not to break a law (Armstrong, 2020; Benoit, Jansson, Smith, \& Flagg, 2017; Mac \& Smith, 2018). It was a criminal offense to keep or to be found in a common bawdy house (Section 210(1)); 
live on the avails of prostitution-applying to anyone who receives a monetary benefit via prostitution (Section 212(1) (j)); and communicate for the purposes of prostitution (Section 213(1)(c)). These laws were challenged in 2010 in the Ontario Supreme Court where three plaintiffs, Terri-Jean Bedford, Amy Lebovitch, and Valerie Scott (all current or former sex workers) argued that certain sections of the Canadian Criminal Code for prostitution-related offences violated their human rights, as laid out in the Canadian Charter of Rights and Freedoms, and endangered sex workers. This court challenge occurred at the same time as The Missing Women Commission of Inquiry was established to examine justice system responses to women reported missing from Vancouver's Downtown Eastside (DTES) and, specifically, the police investigation of Robert William Pickton, the convicted murderer of DTES sex workers (Opal, 2012), creating a unique opportunity structure for sex work movement actors (Hallgrimsdottir \& Benoit, 2007). Justice Himel paid careful attention to the quality of the information presented to her and found some of it lacking, including research provided by academic researchers advocating for the abolition of adult commercial sex:

Although Dr. Farley has conducted a great deal of research on prostitution, her advocacy appears to have permeated her opinions. For example, Dr. Farley's unqualified assertion in her affidavit that prostitution is inherently violent appears to contradict her own findings that prostitutes who work from indoor locations generally experience less violence (Ontario Superior Court of Justice, 2010, p. 353).

Justice Himel went on to state: "Similarly, I find that Drs. Raymond and Poulin were more like advocates than experts offering independent opinions to the court. At times, they made bold, sweeping statements that were not reflected in their research" (Ontario Superior Court of Justice, 2010, p. 357).

After careful review of a large body of legal and social science research reporting diverse perspectives, evidence, and submissions from individuals, anti-prostitution groups, sex worker organizations and their ally agencies, the Ontario Supreme Court Justice Susan Himel struck down the three sections, stating they deprived sellers of their "security of the person," "liberty interests," and increased their risk of being victimized. Moreover, Justice Himel ruled that the laws operated in a manner that was inconsistent with the principles of fundamental justice and individual rights laid out in Canada's Charter of Rights and Freedoms.

After a series of appeals, the case was finally heard by the Supreme Court of Canada (SCC) (indexed as Canada v. Bedford, 2013). The SCC unanimously ruled in favor of the plaintiffs, stating the three challenged sections of the Criminal Code violated Section 7 of the Charter. The SCC decision in the Bedford case was a rare occasion in the history of Canadian sex work regulation that was informed by a "realist" perspective that presumes there is a single external reality which can be elucidated through contexts, processes, and effects, but that this reality is complex (Pawson, 2013) and policy makers should weigh all viewpoints and available empirical evidence (Dunn, Meulen, O'Campo, \& Muntanerd, 2013). Crucially, Bedford and the SCC decision paid serious attention to information provided by active sex workers and their support organizations, legal scholars, social science researchers, harm reduction and other outreach agencies showing that sex work, much like other forms of marginalized work, involves the interplay between constraint and choice in workers' lives (Agustín, 2006; Benoit et al., 2017; Bungay, Halpin, Atchison, \& Johnston, 2011), clearly showing that criminal provisions surrounding the activity worsened their work conditions and hindered their access to police protection and other crucial services (Chu \& Glass, 2013).

The SCC ruled the prostitution laws stay in effect for 1 year; afterward, the sections would be removed from the Criminal Code. Thus, if it chose, the Government of Canada had 1 year to amend new laws and/or develop regulations that would comply with the Charter. As with the Bedford case, a wide range of evidence was submitted to Department of Justice Canada, including from individuals holding different perspectives on sex work and its governance (Department of Justice Canada, 2014a). This included the Canadian Alliance for Sex Work Law Reform (Canadian Alliance), a coalition of peer-driven sex worker advocacy organizations and allied agencies from across Canada formed in 2012 to advocate for law and policy reform that values and defends the rights and safety of sex workers. In addition, the first author and her research team also provided evidence, based on their analysis of data with a heterogeneous sample of sex workers $(N=218)$ who were interviewed for a community-informed study that included more than thirty collaborators from five provinces involved in the study design, data collection, analysis, and interpretation of the findings (Belle-Isle et al., 2014).

However, unlike the SCC decision in Bedford, policymakers among the then majority Conservative government appeared primarily concerned with pleasing their anti-prostitution constituents and hearing evidence from academic researchers and community groups advocating for the 'Swedish model', banning the purchase of sexual services for pay in an effort to end demand (Östergren \& Dodillet, 2011). Bill C-36, the Protection of Communities and Exploited Persons Act (PCEPA), argued that marginalized groups, especially Indigenous women and girls, are disproportionately represented in prostitution and should be protected under the Criminal Code. The empirical evidence about the adverse impact of criminalization of sex work on active Indigenous and other sex workers (Hunt, 2014), including submissions from the Canadian Alliance, whose membership includes community groups participating 
in the research project reported on below, was not referenced in the Government's technical paper. Importantly, this paper provided an overview of the Supreme Court of Canada's findings and rationale for the Government's 2014 legislative response (Department of Justice Canada, 2014a).

According to the PCEPA, sex workers in Canada may do the following: provide sexual services at a fixed indoor location; communicate with others for the purpose of offering or providing sexual services; advertise their own sexual services; and, pay for services with profits from the sale of their own sexual services (e.g., accounting, security) when that compensation is proportionate to the services offered. The PCEPA criminalizes the purchasing of sexual services and receiving material benefits from prostitution and procuring services. Moreover, it makes it illegal for newspaper/magazine publishers, website administrators, and web-hosting services to publish advertisements for any sexual services (Department of Justice Canada, 2014b). The PCEPA also makes it illegal for workers to communicate their services in a public place next to a school ground, playground, or daycare center, having greater negative impact on more economically disadvantaged sex workers, including Indigenous and transgender sex workers, and those with problematic substance use (Benoit et al., 2009; Canadian Public Health Association, 2014; Krusi et al., 2012; Kunimoto, 2018; Lyons et al., 2017; Orchard, Farr, Macphail, Wender, $\&$ Young, 2012). In essence, the PCEPA is one of the most extensive instruments of criminalization globally (O'Doherty $\&$ Waters, 2019), and leaves sex workers in a precarious victim-criminal position (Majic, 2014).

\section{Method}

\section{The Study: Initial Proposal}

Beyond the 'Missing Women Inquiry': Empowering sex workers as social justice advocates, was funded by a 3-year fellowship (2018-2021) from the Pierre Elliott Trudeau Foundation (PETF), an independent and non-partisan charity established in 2001, as an ongoing tribute to the former prime minister. The fellowships are awarded on the basis of the fellow's proposal of a project-a knowledge production and dissemination initiative that is grounded in engagement, in areas of importance to Canadians. The fellow holder, the first author, is of Indigenous background and has long been engaged in public discourses about the rights of disadvantaged groups: Indigenous and non-Indigenous midwives; birthing women desiring a healthy experience of pregnancy and childbirth; street-involved youth exiting government care; Indigenous and non-Indigenous pregnant women dealing with substance use, poverty and other life challenges; and adults who sell sexual services. Her project focused on human rights and dignity for one of Canada's most marginalized groups- people engaged in sex work. The project was informed by the inquiry into missing and murdered Indigenous women and girls, the majority who identified as Indigenous and sold sexual services to make a living (National Inquiry into Missing and Murdered Indigenous Women and Girls, 2019).

Envisioned was a project that would bring together small groups of Indigenous and non-Indigenous sex workers $(N=10-12)$ in a number of Canadian cities in a face-to-face, peer-led program to train them as 'social justice advocates', to learn about the PCEPA, document their stories about its strengths and weaknesses, and prepare them to respond to the Government's mandated review of the PCEPA within 5 years of its implementation. The project aimed to avail of this new policy window to educate the diversity of sex workers and be prepared to pressure the Government to enact future legislation that responded to their actual needs and circumstances, in a manner that both meets legislative purposes and endures future constitutional challenges. Potential knowledge users include: members of government, service and advocacy agencies representing other marginalized populations, protection, health, and social service care providers. Given the nature of the envisioned project - an iterative process driven by experiential sex workers (Benoit et al., 2017), the first author decided not to partner with knowledge users whose views on sex work did not directly align with those of her core participating community groups that belonged to the Canadian Alliance.

The PETF project would involve five participating community groups selecting the trainees, aiming for diversity in demographic backgrounds and sex work history. Criteria would also include interest in wanting to learn about laws and policies that affect sex workers' health, safety, and human rights, being 19 years of age or older, and currently engaged in sex work in the particular research city. Attendees would receive stipends for their involvement in the program; in addition, food and transportation would be covered by project funds. It was also expected that the training curriculum would be co-developed by the participating community groups. Data sources would include: attendee journaling, anonymous feedback forms, and annual in-person interviews conducted by the first author with members of participating community groups, with the main aim of checking in about how the project was going over the 3-year research program.

\section{Tailoring the Research Focus}

Identifying mobilization of sex workers as the priority Subsequent to the funding announcement in May 2018, a series of teleconference calls took place with representatives from four of the community groups involved in the original research application (one organization was going through transitions and unable to participate at the time). During these calls, group representatives articulated their excitement about the potential of the PETF project to better equip sex workers to occupy 
spaces of power, but wondered if the original research purpose could be nuanced to a focus specifically on the challenges of mobilizing sex workers in their particular communities. They noted that sex workers have been formally developing collectives since the early 1970's, speaking out against the criminalization of sex work and demanding decriminalization of adult sex work and realization of their social rights. However, mobilizing sex workers around their social and human rights takes dedicated time and funding. Group representatives noted the PETF project created a unique opportunity to do so and, if successful, would help their organizations to grow and diversify their membership at the local level, while training interested sex workers in activism, including marginalized Indigenous and migrant sex workers, and those who use substances. In response, group representatives recommended the following: (1) the project recruit two additional sex worker groups that had recently opened their doors, and (2) bring representatives from the six organizations together for an in-person two-day strategic planning meeting. While all of these sex worker and allied groups were members of the Canadian Alliance, they varied in the percentage of experiential staff, the services provided, range of patrons, programs and resources, as well as advocacy work.

The two-day strategic planning meeting was organized by the first author and held in Montréal, November 2018. Those attending spoke about the difficulties they were facing in finding resources to fund their outreach programs, the challenge of balancing service provision and activism for sex workers, and the negative impact of the PCEPA on the ability of the sex workers seeking their services to make a living and keep safe. Despite these challenges, attendees agreed that our emerging research project had the potential to bring the diverse groups of sex workers together and learn about ways to mobilize around their rights and at the same time to strengthen their organizations.

Development of SWASFG Subsequent to the strategic planning meeting, the first author distributed a revised research plan that would more squarely focus on the development of content - what became called, 'Sex Workers' Activist School Facilitation Guide' (SWASFG). In addition, a proposal to reshuffle the research budget to support its development and implementation in the communities where the project's participating organizations were located was circulated. The revised research plan was discussed in follow-up teleconference calls, as well as issues related to how the research funds should be distributed and who should be involved in drafting the SWASFG. Participating community members argued that only organizations that had currently active sex workers on staff should be directly involved in the curriculum development, and that research funds should be directed to their organizations to free up some of their work time for curriculum development, with additional funds going to the individuals who put in more time and effort. Two participating community agencies did not have any sex work experiential staff employed at the time and agreed to step aside during the curriculum development stage, but renewed their involvement when the training modules were ready for review. Team members also discussed what tools should be used to collect information on the unfolding IKT process in which they were collectively engaged. All agreed that a series of openended recorded interviews conducted by the first author with participating group representatives would be the best data collection strategy for the emergent project. In follow-up teleconference calls, discussion also ensued regarding the first and second authors' role on the subcommittee tasked with developing the training modules. The consensus decision was that they should organize the meetings, keep minutes, and edit the modules, but not give direct input regarding content.

After much discussion among the subcommittee tasked with developing the curriculum, the current form of the SWASFG is a series of modules with the following specified objectives: (1) defining and understanding sex worker rights', activism, accountability, ally-ship, leadership, public speaking, and working with the media; (2) suggested activities to illustrate each module's objectives; (3) a list of materials to support each module; and (4) evaluation tools for the modules. The Guide also recognizes the need for further reflection and engagement on how to maintain and support sex workers in social movements and how to address the barriers that prevent mobilization. The plan going forward is to implement the mobilization training programs in each of the six communities in 2020-2021. A portion of the research budget will be distributed equitably across the participating community organizations, although the more established partners have related they may be able to fund some of the activities in house and some partners are discussing a joint training effort in one of their communities.

Interview procedure Below, we present the summary findings from in-person and telephone interviews $(N=10)$ with members (henceforth called, 'interviewees') from our participating community groups about their views on the unfolding research process to date. All of the interviewees had attended the 2-day Montréal planning meeting and participated on most of the teleconference calls and received the minutes for the meetings. They were thus familiar with the unfolding of the project and had helped shape its trajectory. Only one individual who had participated in the research process since its inception did not respond to our request to be interviewed. The interviewees identified as women, were employed part or full time by their organization/agency in a variety of activities, including administration, programming, outreach, and advocacy. Many had been active in these roles for many years. Ethics approval for this portion of the study was obtained from the authors' institution, the University of Victoria, Canada. Verbal informed consent was obtained from all interviewees and permission was granted for the use of audio-recording equipment 
during the interview. Interviewees were assured of their ability to end the interview at any time and the confidentiality of the data they shared with researchers.

The interview schedule consisted of 12 open-ended questions, co-developed with the research team. During team teleconference calls, it was agreed that the first author would create an initial draft of these research questions and interviewees were invited to review and give feedback on the draft questions. All did so and made recommendations to ensure the questions were not personalized, but rather were focused on their organizations and the developing research project. Interviews, ranging in length from 30 to $60 \mathrm{~min}$, were all conducted by the first author. To acknowledge their time, knowledge and expertise, interviewees received an honorarium of $\$ 100$ (CAD), which some said they would donate to their organization. All audio recordings were transcribed and identifying details were redacted. The transcribed interviews were then sent to interviewees to check for accuracy. A few interviewees requested removal of small passages of text that were potentially identifying for their organizations.

Thematic analysis Below we present our thematic analysis of interviewees' answers to this subset of questions that focused on: (1) difficulties mobilizing the diversity of sex workers; (2) why their organization decided to become involved in the PETF project, and, (3) their thoughts on the shared research process to date, as well as suggestions going forward. We decided to report on this subset of questions because they captured the ongoing, dynamic interactions among us as researchers and our diverse group of community partners attempting to reshape the research process to better address what they had identified as a complex problem facing sex workers in their communities.

The transcribed answers were coded thematically using NVivo 10 software, according to Braun and Clarke's (2006) six principles for thematic analysis, beginning with familiarization with the data by closely reading the interview transcripts. The authors independently coded each answer to reach consensus about the thematic interpretation of the data, which were then organized into master files (mobilization, engagement, research progress, funding, challenges) by the second author. The data were then reviewed using line-by-line coding and an iterative, constant comparative process to identify more nuanced themes relative to the master codes, interview transcripts, and revised research aims. To enhance reliability, the authors met to discuss the coded themes. Discrepancies were discussed and agreement was reached on the final coding scheme, which the second author applied to the transcripts (Bradshaw \& Stratford, 2010).

\section{Results}

\section{The Challenge of Mobilizing Sex Workers}

Interviewees expressed the need for a sex worker training program to address the ongoing challenge of bringing sex workers from different backgrounds together in their organizations, particularly those who are the most marginalized. One interviewee related, "people who carry a lot of, or live a lot of intersecting identities, don't always have kind of the luxury or the access to the kind of mobilization and advocacy that I' $m$ thinking of anyways, um, when all those other things come first just to meet basic needs." Another interviewee explained the challenges related to diversity and how the oppression that exists within the diverse sex worker population is reflected in larger societal divisions: "the discrimination against other group[s] of sex worker[s], like people using drugs, or the... sex workers [who are] Indigenous, or even other racialized sex workers... Because our society always like, um, training the people to exclude the other people, right?" She elaborated:

[L]ike we've seen in many other movements-people who are racialized, people who are trans, people who are poor and drug using, are constantly fighting to have their voices heard and validated. And, our movements, collectively, are often dealing with racism, dealing with classism, dealing with ableism... These issues exist because they exist in our world. And so it's hard to mobilize diverse communities because we are all living under those structures.

Associating with marginalized sex workers sometimes causes more privileged sex workers anxiety and may lead to prejudice: "There's so much judgment within community, and there's so much othering. And that, I believe, comes from a place of fear. Of, of um...you know, if we, if we move too close to people who are heavily criminalized or heavily stigmatized, that's a potential for that to shift to us. [It] is, is scary."

Interviewees highlighted these challenges make it difficult to articulate collective goals. As one of them explained:

There is no real collective consensus on what sex workers need... So it's hard to come together under a united banner, when our needs and experiences are so very different. It means that we don't have simple, singular messaging. We have multi-faceted, complex, nuanced, ever-changing and adapting messaging and advocacy and focus. 
This interviewee reflected that her organization's work is often focused on responding to issues that come up, rather than being proactive about sex workers' needs and rights: "our work is reactive...our agendas, we are often reacting to laws, to violence, to counter-arguments, to human rights violations, to basic needs for survival. So, it's very difficult to mobilize when you are constantly under stress and always reacting."

One way of breaking down barriers and bringing together diverse groups of sex workers is to invite them to the team: "When there's drug users on the team, it's easier to mobilize sex workers who are drug users. When there's Indigenous women on the team, it's easier to mobilize Indigenous sex workers. Um, because people like to see themselves in the organization and the staff represents the organization." Interviewees hoped that the proposed training might help their organizations overcome some of these mobilization challenges. In the words of this interviewee:

So we see the benefit, for example, of having these groups of people come together to feel safe, and then we also see the benefit of having groups where there is a real wide range of diversity of what kind of sex work people are doing, their backgrounds... [I]t's really beautiful to see that when you start to see those barriers being broken down, and people understanding that they're doing the same work, and they have a lot of the same challenges, and we're kind of all in this together.

\section{Reasons for Engagement}

Interviewees agreed to engage in the project for an assortment of reasons. Familiarity with the first author on other research projects was mentioned. According to one interviewee, "Those are people that I've worked with, and that I have community with, and that I trust... and I felt like you were really open to, um, giving us the reins in terms of how this moved along. Right? So that kind of felt, that felt good." Another interviewee noted: "My own philosophy around research-which I don't know if I've shared with you over the years - has been that all research needs to do this, needs to respond to community." This individual had heard about the project through another training that took place at their organization, which was led by the first author, and shared that those involved in this training "felt mobilized within that process. And just how it was really. People were feeling empowered and energized." She went on to note that this was a contrast to how she had felt after the PCEPA was enacted, that "people have been really frustrated and feeling beaten down around the laws." She elaborated:

And I thought that the work that you were doing to not have a top-down approach, to have a very, um, unstructured idea that would grow and build from the ideas and the needs that sex workers identify and address to you. Ah, I think it's a good model. And I also imagine that it was probably tricky for ethics approval given the unstructured nature, at least in the beginning, which ultimately allowed at lot of freedom and power for sex workers to occupy in the development of the project.

The lack of funding for projects that mobilize sex workers through activism and promote their rights was another reason mentioned for involvement. Interviewees said they felt validated by their lived experiences as sex workers when they learned about the flexible nature of the project, as one of them highlighted, "We're saying we want to mobilize sex workers, and I think that it's a really great way to honor people's voices. And honor, you know, them taking the lead on this battle and really informing what we want to see for change. I think that all research should be like that." Another interviewee put it this way:

I think it was a bit shocking to me too...It's essential the work that a lot of us want to do anyways, but we don't usually have time or resources for it...so, that's, that's quite a gift, um, I would say to communities to be able to think about: okay, lets really actually put some energy into focusing on how to create bigger movements, and better movements, and more social justice advocates.

Other reasons mentioned for involvement were to deepen ties among themselves. One of them put it this way: "I think having the opportunity to learn from each other and work with each other; I think this felt like valuable. And, and this has been missing." Newly established community partners with limited contacts and resources found this process especially valuable:

As a relatively small, relatively new program, it was really exciting and important for [organization] to be a participant, um, as kind of a key representative of sex workers, and sex worker advocacy in the [region]. In a lot of ways the work that we do, and um, the way that we work is very much isolated...So I think that being able to participate, and to be engaged in the work in this way was really, really significant for us. Both because of the-like I mentioned-the young age of our program and the relatively small staff team, and even numbers of participants compared to other programs, um, I think it was really significant for us to, kind of, have a foot in this way.

Some interviewees also said they were involved because of the project's potential for them to better connect with more marginalized sex workers in their local community: "This is a big project we should be involved in because we felt that, um, it was a really good chance to hear the 
voice of populations that have been voiceless for so long." Another interviewee stated: "I hope that this project can help to...empower different group[s] to do the mobilizing. Particular to be more inclusive with those marginalized and excluded."

\section{Benefits and Challenges of the Participatory Research Progress}

Interviewees said they were largely satisfied with the course the project has made in its first stage of operation. They were appreciative that its aim had evolved to a clear focus on what they identified as an unmet need in the national sex work community. One individual expressed: "I feel...that this study [has] really like honored the community in the way that really listening, um, to what sex workers want in and the way that it's evolved to mobilize sex workers-which I think is amazing." Another reflected: "I do remember the project shifting and evolving very quickly, and I remember feeling like that was very fantastic."

Interviewees also appreciate how the research process helped them engage across their communities. This interviewee appreciated "having the collective meetings, alsobecause I think this is very empowering, and important that people can come together." Another reflected: "So I think that being able to participate, and to be engaged in the work in this way was really, really significant for us." Another interviewee summed up the process as "a real exercise in trust, and allyship, and community development." This interviewee put it like this:

The upside is that there will be, ideally, there's going to be more engagement across the various groups involved. There will be things learned. Like, people will produce, um, ideas for the curriculum that otherwise wouldn't have been there, that reflect maybe their unique circumstance or where they're coming from. So they'll be learning across the groups as a process of developing the curriculum. And it's probably again, kind of necessary in order for people to engage with the process and feel a sense of satisfaction around having their voices heard.

Flexibility in how the research funds were used was additionally brought up by interviewees as a benefit. One individual stated:

I guess that the funding allows to do it. I think that is very important that [you] can respond to the lead recommendation of the sex worker, right? I think this is extremely important, the funder should not lead the direction of how this money should be spent. And also create the flexibility for the people that run the Project, that in the process they can change how the money is allocated. So, extremely important.
Another commented:

Well, I think that that is a beautiful thing. I mean, I think that's the best practice in terms of how to do that process. You included us all in the conversation about the funding, what was available, and how to, how to allocate it or share it. And I think that I felt like everybody came in an honorable way.

Some interviewees were especially delighted that the project was able to fund, when needed, community partner release time and other costs involved in the development of the SWASFG. One commented:

I think it's great because every community has different needs, and has different niches. Well, I think that for the honorariums and travel and all that stuff, it's really honoring of the work. Like we're saying we want to mobilize sex workers, and I think that it's a really great way to honor people's voices. And honor, you know, them taking the lead on this battle...And really informing it to what we want to see for change. I think that all research should be like that...yah, the community is able to say, we need more here and there. Because every community is a little bit different. And we're able to kind of be flexible. And, you know, really use that money for, um, what works in one community might not for another. So really use it to, um, better that community.

Adaptable timelines were appreciated by some interviewees. They said they were initially concerned about having to meet the original research schedule and relieved when it was amended. One expressed: "I think people have really appreciated the flexibility around timing and what's kind of doable. And even, you know, being able to re-look at dates." The flexible timing was needed in order to have everyone's input. As one of them reflected:

I don't really have a basis of comparison for are we on track or are we not compared to other experiences or research projects I've been involved with. So, I don't know! I would say yes? Because I think the process needed time. And, um, things are moving forward. And I'm also feeling like we are thankful that we have had time to, to make those connections and connect with other people and give feedback when we were able to.

Another said, "regarding the timeline and the delivery of training... I don't feel that it's been rushed in anyway, or, um, like pulled out for too long in any way either. So I'd say we're probably just about, just you know, kind of honoring the research. I don't know if you'd agree, what timelines you needed, but [this is] from a community member perspective."

These various benefits of the IKT process were accompanied by challenges. One related to leadership, as one 
interviewee shared that the emerging project has all "sort of personalities involved, just like sex worker organizing, you get a lot of leaders."

Some interviewees said the collaborative participatory approach and the lack of a single leader created some confusion about what tasks they should be doing. One individual put it this way: "[It was] maybe at times unclear for people if they're doing the right thing. Like, 'Is this what people want from me?' These are kind of some of the questions I've fielded from people involved from our organization." A related challenge was bringing together community partners with different organizational priorities. One interviewee related: "Is just that we all have such different styles of organizing. And also we all have different priorities....So, um, I think originally I thought, oh, this is a great idea, but I don't know what kind of skill there is across the country to produce this kind of thing." Later this interviewee reflected that she appreciated the challenge: "And so we have the, the privilege of learning through this process, instead of the pressure of making something happen."

When asked if they had any advice going forward to ensure the project is successful, some interviewees said they thought we should continue what we were doing. One requested continued "regular, meaningful engagement with people with lived experience." Another stated: "just, you know, the things that have happened already, like timeframes or needs or even guides." This person put it this way: "listening, and bringing people together, and then being responsive to people's needs around what kind of resources do they have in place to invest the time." This interviewee said she had "been observing you pushing your own boundaries in different ways to do something that's quite different from the research you've produced before. [T] his is something that I very much value in... an ally."

One interviewee advised that our research process be shared with other researchers:

I think that what you're doing is extremely important and a very good model. You now, that to really create a real space where the sex worker can contribute expertise, and being support, and be involved in the Project. And I think that is very, very relevant to educate other researchers.

Finally, this interviewee warned we need to pay attention to research needs and the dynamic of the group:

I would love for you to be able to engage or participate or be present for the ally-ship piece [of the training]. I think it would be really great for your work and for the, the research...But ah, it's how can we make sure that you, that you get what you need from it without, without the issue of shifting the dynamic.

\section{Discussion}

The goal of this article has been to document and evaluate the IKT research process (Bowen \& Graham, 2013; CIHR, 2015; Gagliardi et al., 2015) we have been engaged in during the first year of operation of a PR project focused on gaining knowledge about one marginalized and stigmatized group at the bottom of vulnerability hierarchiesadults who sell sexual services (Arnott \& Crago, 2009; Benoit et al., 2019; Cargo \& Mercer, 2008). Sex workers and the community groups representing them have been calling for research that is truly collaborative (Wagenaar et al., 2017), where researchers and those representing sex workers come together as equal partners participating in consensus-oriented decisions across the entire research process (Lowthers et al., 2017; Masuda et al., 2008). This call resonates with the aim of the KTA framework (Graham et al., 2006) that envisions an iterative process between academic researchers and their partners actively engaged in creating knowledge and interpreting results for real-world application (Field et al., 2014).

The initial aim of the PETF project, mainly conceived by the first author, was to work collaboratively with sex worker and allied organizations to develop a training program that would bring Indigenous and other sex workers together to learn about the strengths and weaknesses of Canada's criminal justice approach to adult sex commerce. What has transpired instead has been a gradual alteration in the research program to a focus on the mobilization of sex workers in their communities around their diversity, as well as their occupational and social rights. Interviews with members of participating sex worker and allied organizations showed they collectively agreed that training sex workers about their diversity and how to mobilize their occupational and social rights was an ideal way to refocus the research funds to help sex worker organizations and allied agencies achieve some of their longer-range goals. Being open to change, after inviting community partners to the research table is especially important for sexual minorities and other marginalized groups who face daily indignities and is one way to gain trust and maintain a facilitative process (Anasti, 2017; Hoefinger et al., 2019). In this way, the actual topic of research is less important in collaborative research projects than the process undertaken. This two-way process also requires attention to personal factors if mutual trust is to be developed and sustained (Bowen \& Graham, 2013). Many of those interviewed for this article mentioned they became engaged in the PETF project because of the first author's reputation when engaging with the sex work community and with her willingness to redirect research funds to fill a knowledge gap around mobilization that they trusted would bring about positive social 
change for the sex work community. While the funding for this project is in the form of a fellowship that involves flexibility regarding how research monies are allocated, even government research institutes and councils (e.g., Canadian Institutes of Health, Social Sciences and Humanities Research Council) are likely more flexible about changing the research focus than researchers assume.

Those interviewed mentioned a number of benefits from their engagement thus far, including the opportunity to share experiential knowledge and previously compiled resources to co-develop a training program focused on mobilizing sex workers about their rights and their collective identity, to work collaboratively together despite their geographical isolation across the country, and access research funds to help them build their capacity to participate over time. The project to date has also been beneficial to the researchers. The adjusted PETF project has provided us with valuable knowledge about community partners and their organizational resource capacity. In addition, we have gained important knowledge about how to negotiate with community partners that differ in important ways, but are unified in the opinion that sex work in Canada should be decriminalized and the basic human rights of sex workers upheld. Our learnings include that our community partners are linked nationally in alliances, they communicate frequently about research on, about and with sex workers, they honor being included as equal partners at the research table, and they appreciate equitable distribution of research resources.

Yet, our iterative research process has not been seamless (Benoit et al., 2005; Eccles, 1996; Rhodes, Malow, \& Jolly, 2010). Interviewees drew attention to disconcerting shifts in timelines. This concern will likely persist as we move forward with the mobilization training, especially given the current global Covid-19 pandemic that has had a devastating impact on sex workers and organizations providing outreach. Balancing power between the academic leader and community representatives has been a concern during the first stage of our project and will likely endure across the action cycle. Open discussion among the team during virtual and face-to-face meetings about how to share this power will be required during the next stages. A related challenge is reaching consensus on research plans among community partners that vary in their organizational histories, their clientele, and the services they provide. This finding highlights the importance of ongoing relationship building through continuous online and in-person team engagement to help sustain the trust and shared culture that has been built during the early research stage. Other researchers have noted that it takes much time for community members to "grow into" the project and "build trust, develop a shared culture, identify common priorities, and undertake collaborative research" (Bowen \& Martens, 2005, p. 207).

Our study had several limitations. Firstly, there is a risk of bias and subsequent error given the first author is in control of the research funds, recruited the initial community organizations, conducted most of the in-person interviews, and co-analyzed the findings. If carefully monitored during the next research phase, the PR approach that has been established during the first research phase will help the team strike the right balance of power among academic and community team members. Evaluation data were only collected through a small number of qualitative interviews with community team members, limiting the generalizability of the findings regarding the strengths and weaknesses of the iterative knowledge translation process described. It will be insightful to find out if the emergent themes generated from these interviews in early stages of the project are repeated in subsequent interviews.

\section{Conclusion}

Partnered research with communities has become more widespread in social science and health research and increasingly a requirement of research institutes and agencies. Most recently, marginalized groups such as sex workers and the organizations providing peer support and advocacy on their behalf, are asking to be invited to sit at research tables from the onset of research. This article has argued it is important to begin authentic collaboration from the beginning of the research process if the knowledge is to be eventually beneficial when taken up in practice. The IKT process is necessarily time-consuming as community and academic partners have to become adequately informed about each other's knowledge bases, research cultures, and organizational priorities before mutual trust is achieved and work can take place on co-developing research priorities and strategies.

Although academic partners might be inclined to develop research questions that respond to trends, gaps, and debates in the academic literature, if reducing the know-do gap is the end goal, they must remember that marginalized groups are unlikely to be interested in the answers to research questions that they do not have a part in developing. Since the KT literature is largely focused on research uptake by public sector policy and program experts in formal health care institutions and government bodies, a case can be made to include resource poor organizations located within the nonprofit sector in the discussion. Their daily access to and hands-on knowledge of those they serve, in addition to unique capacity to translate findings directly into practice and program innovations, are important reasons as to why they should be included from the onset at the research table.

Funding The funding was provided by the Pierre Elliott Trudeau Foundation (Grant No. 5689). 


\section{Compliance with Ethical Standards}

Conflict of interest The authors declare that they have no conflict of interest.

Ethical Approval Approval was obtained from the ethics committee of the University of Victoria.

Informed Consent Informed consent was obtained from all individual participants included in the study.

\section{References}

Agustín, L. M. (2006). The conundrum of women's agency: Migrations and the sex industry. In M. O'Neill \& R. Campbell (Eds.), Sex work now (pp. 116-140). Cullompton, England: Willan Publishing.

Anasti, T. (2017). Radical professionals?: Sex worker rights activists and collaboration with human service nonprofits. Human Service Organizations: Management, Leadership and Governance, 4(41), 416-437.

Armstrong, L. (2020). Decriminalisation of sex work in the post-truth era? Strategic storytelling in neo-abolitionist accounts of the New Zealand model. Criminology \& Criminal Justice. https://doi. org/10.1177/1748895820918898.

Arnott, J., \& Crago, A. (2009). Rights not rescue: A Report on Female, Male, and Trans Sex Workers' Human Rights in Botswana, Namibia, and South Africa. South Africa: Open Society Institute.

Belle-Isle, L., Benoit, C., \& Pauly, B. (2014). The role of community organizations in addressing health inequities through participatory processes. Action Research Journal, 12, 177-193.

Benoit, C., Jansson, M., Millar, A., \& Phillips, R. (2005). Communityacademic research on hard-to-reach populations: Benefits and challenges. Qualitative Health Research, 15(2), 263-282.

Benoit, C., Jansson, M., Smith, M., \& Flagg, J. (2017). "Well, it should be changed for one, because it's our bodies": Workers' views on Canada's punitive approach towards sex work. Social Sciences, 6(2), 52.

Benoit, C., Jansson, M., Smith, M., \& Flagg, J. (2019). Prostitution stigma and its effect on the working conditions, personal lives and health of sex workers. Journal of Sex Research, 55(4-5), 457-471.

Benoit, C., Shumka, L., Phillips, R., Hallgrímsdóttir, H., Hankivsky, O., Kobayashi, K., ... Brief, E. (2009).Explaining the health gap between girls and women in Canada. Sociological Research Online. https://doi.org/10.5153/sro.2024.

Bernstein, E. (2010). Militarized humanitarianism meets carceral feminism: The politics of sex, rights, and freedom in contemporary antitrafficking campaigns. Signs: Journal of Women in Culture and Society, 36(1), 45-71.

Bess, K., Prilleltensky, I., Perkins, D., \& Collins, L. (2009). Participatory organizational change in community-based health and human services: From tokenism to political engagement. American Journal of Community Psychology, 43, 134-148.

Bowen, S., \& Graham, I. (2013). Integrated knowledge translation. In S. Straus, J. Tetroe, \& I. D. Graham (Eds.), Knowledge translation in health care: Moving from evidence to practice (2nd ed., pp. 14-21). Hoboken, NJ: Wiley.

Bowen, S., \& Martens, P. (2005). Demystifying knowledge translation: Learning from the community. Journal of Health Services Research \& Policy, 10, 203-211.

Bradshaw, M., \& Stratford, E. (2010). Qualitative research design and rigour. In I. Hay (Ed.), Research methods in human geography (pp. 69-80). New York: Oxford University Press.
Braun, V., \& Clark, V. (2006). Using thematic analysis in psychology. Qualitative Research in Psychology, 3, 77-101.

Bungay, V., Halpin, M., Atchison, C., \& Johnston, C. (2011). Structure and agency: reflections from an exploratory study of Vancouver indoor sex workers. Culture, Health \& Sexuality, 13, 15-29.

Canada vs. Bedford. (2013). R.S. C. 2013, SCC 72.

Canadian Institutes of Health Research (CIHR). (2015). Guide to knowledge translation planning at CIHR: Integrated and end-of-grant approaches. Retrieved January 20, 2020 from: https://cihr-irsc. gc.ca/e/45321.html.

Canadian Public Health Association. (2014). Sex work in Canada: The public health perspective. Retrieved January 20, 2020 from: www. cpha.ca/uploads/policy/sex-work_e.pdf.

Cargo, M., \& Mercer, S. L. (2008). The value and challenges of participatory research: Strengthening its practice. Annual Review of Public Health, 29, 325-350.

Chu, S., \& Glass, R. (2013). Sex work law reform in Canada: Considering problems with the Nordic Model. Alberta Law Review, 51, 101-124.

Department of Justice Canada. (2014a). Online public consultation on prostitution-related offences in Canada-Final Results. Retrieved January 20, 2020 from https://www.justice.gc.ca/eng/rp-pr/other -autre/rr14_09/index.html.

Department of Justice Canada. (2014b). Technical Paper: Bill C-36, Protection of Communities and Exploited Persons Act. Retrieved January 20, 2020 from www.Justice.Gc.Ca/Eng/Rp-Pr/Other -Autre/Protect/P1.Html.

Dunn, J., van der Meulen, E., O'Campo, P., \& Muntanerd, C. (2013). Improving health equity through theory-informed evaluations. Evaluation and Program Planning, 36, 184-190.

Eccles, J. (1996). The power and difficulty of university-community collaboration. Journal of Research on Adolescence, 6(1), 81-86.

Field, B., Booth, A., Ilott, I., \& Gerrish, K. (2014). Using the knowledge to action framework in practice: A citation analysis and systematic review. Implementation Science, 9(1), 172. https://doi. org/10.1186/s13012-014-0172-2.

Flicker, S., Wilson, M., Travers, R., Bereket, T., McKay, C., Van der Meulen, A., \& Van der Rourke, S. B. (2009). Community-based research in AIDS-service organizations: What helps and what doesn't? AIDS Care, 21(1), 94-102.

Gagliardi, A. R., Berta, W., Kothari, A., Boyko, J., \& Urquhart, R. (2015). Integrated knowledge translation (IKT) in health care: A scoping review. Implementation Science, 11, 38. https://doi. org/10.1186/s13012-016-0399-1

Graham, I., Logan, J., Harrison, M., Straus, S., Tetroe, J., Caswell, W., \& Robinson, N. (2006). Lost in knowledge translation: Time for a map? Journal of Continuing Education in the Health Professions, 26(1), 13-24.

Hallgrimsdottir, H., \& Benoit, C. (2007). From wage slaves to wage workers: Cultural opportunity structures and the evolution of the wage demands of the Knights of Labor and the American Federation of Labor, 1880-1900. Social Forces, 85(3), 1393-1412.

Hoefinger, H., Musto, J., Macioti, P. G., Fehrenbacher, A., Mai, N., Bennachie, C., \& Giametta, C. (2019). Community-based responses to negative health impacts of sexual humanitarian anti-trafficking policies and the criminalization of sex work and migration in the US. Social Sciences, 9(1), 1. https://doi.org/10.3390/socsci9010 001.

Hunt, S. (2014). Representing colonial violence: Trafficking, sex work, and the violence of law. Atlantis: Critical Studies in Gender, Culture \& Social Justice, 37(2), 25-39.

Hunter, D. (2019). Meeting the challenge of the "know-do" gap: Comment on "CIHR health system impact fellows: Reflections on "driving change' within the health system". International Journal of Health Policy Management, 8(8), 498-500. 
Jürgens, R. (2005). 'Nothing about us without us': Great meaningful involvement of people who use illicit drugs: A public health, ethical, and human rights imperative. Toronto, ON: Canadian HIV/ AIDS Legal Network.

Krusi, A., Chettiar, J., Ridgway, A., Abbott, J., Strathdee, S. A., \& Shannon, K. (2012). Negotiating safety and sexual risk reduction with clients in unsanctioned safer indoor sex work environments: A qualitative study. American Journal of Public Health, 102, 1154-1159.

Kunimoto, E. (2018). A critical analysis of Canada's sex work legislation: Exploring gendered and racialized consequences. Stream: Inspiring Critical Thought, 10(2), 27-36.

Lowthers, M., Sabat, M., Durisin, E., \& Kempadoo, K. (2017). A sex work research symposium: Examining positionality in documenting sex work and sex workers' rights. Social Sciences, 6(2), 39. https://doi.org/10.3390/socsci6020039

Lyons, T., Krüsi, A., Pierre, L., Kerr, T., Small, W., \& Shannon, K. (2017). Negotiating violence in the context of transphobia and criminalization: The experiences of trans sex workers in Vancouver, Canada. Qualitative Health Research, 27(2), 109-182.

Mac, J., \& Smith, M. (2018). Revolting prostitutes: The fight for sex workers' rights. New York: Verso Books.

Majic, S. (2014). Beyond "victim-criminals": Sex workers, nonprofit organizations and gender ideologies. Gender and Society, 28(3), 463-485.

Masuda, J., McGee, T., \& Garvin, T. (2008). Power, knowledge, and public engagement: Constructing 'citizenship' in Alberta's industrial heartland. Journal of Environmental Policy \& Planning, 10(4), 359-380.

Minkler, M. (2010). Linking science and policy through communitybased participatory research to study and address health disparities. American Journal of Public Health, 100(S1), S81-S87.

National Inquiry into Missing and Murdered Indigenous Women and Girls. (2019). Reclaiming power and place: The Final Report of the National Inquiry into Missing and Murdered Indigenous Women and Girls. Retrieved February 1, 2020 from https://www.mmiwg -ffada.ca/final-report/.

Norman, T., \& Pauly, B. (2013). Including people who experience homelessness: A scoping review of the literature. International Journal of Sociology and Social policy, 33, 136-151.
O'Doherty, T., \& Waters, I. (2019). Gender, victimization, and commercial sex: A comparative study. Atlantis, 40(1), 18-31.

Ontario Superior Court of Justice. (2010). Bedford v. Canada onsc 426.

Opal, W. (2012). Forsaken: The Report on the Missing and Murdered Women Commission of Inquiry. British Columbia. Retrieved January 20, 2020 from http://www.ag.gov.bc.ca/public_inquiries/docs/ ForsakenES.pdf.

Orchard, T., Farr, S., Macphail, S., Wender, C., \& Young, D. (2012). Sex work in the forest city: Sex work beginnings, types, and clientele among women in London, Ontario. Sexuality Research and Social Policy, 9, 350-362.

Östergren, P., \& Dodillet, S. (2011, March 3-4). The Swedish Sex Purchase Act: Claimed success and documented effect. Presented at the International Workshop: Decriminalizing Prostitution and Beyond: Practical Experiences and Challenges, The Hague, the Netherlands.

Pawson, R. (2013). The science of evaluation: A Realist manifesto. London: Sage.

Platt, L., Grenfell, P., Meiksin, R., Elmes, J., Sherman, S. G., Sanders, T., ... Crago, A. L. (2018). Association between sex work laws and sex workers' health: A systematic review and meta-analysis of quantitative and qualitative Studies. PLoS Medicine, 15(12), e1002680-54. https://doi.org/10.1371/journal.pmed.1002680.

Rhodes, S., Malow, R., \& Jolly, C. (2010). Community-based participatory research: A new and not-so-new approach to HIV/AIDS prevention, care, and treatment. AIDS Education and Prevention, 22(3), 173-183.

Thomas, R. M. (2009). From 'toleration' to zero tolerance: A view from the ground in Scotland. In J. Phoenix (Ed.), Regulating sex for sale: Prostitution policy reform in the UK (pp. 121-136). Bristol, England: Policy Press.

Wagenaar, H., Amesberger, H., \& Altink, S. (2017). Designing prostitution policy: Intention and reality in regulating the sex trade. Bristol, England: Polity Press.

Publisher's Note Springer Nature remains neutral with regard to jurisdictional claims in published maps and institutional affiliations. 